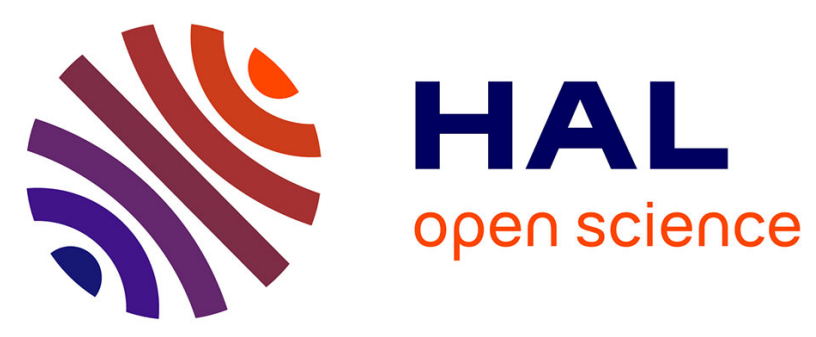

\title{
Potassium Ions Enhance Guanine Radical Generation upon Absorption of Low-Energy Photons by G-Quadruplexes and Modify Their Reactivity
}

Behnaz Behmand, Evangelos Balanikas, Lara Martinez-Fernandez, Roberto Improta, Akos Banyasz, Gérard Baldacchino, Dimitra Markovitsi

\section{To cite this version:}

Behnaz Behmand, Evangelos Balanikas, Lara Martinez-Fernandez, Roberto Improta, Akos Banyasz, et al.. Potassium Ions Enhance Guanine Radical Generation upon Absorption of Low-Energy Photons by G-Quadruplexes and Modify Their Reactivity. Journal of Physical Chemistry Letters, 2020, pp.13051309. 10.1021/acs.jpclett.9b03667 . hal-02469033

\section{HAL Id: hal-02469033 https://hal.science/hal-02469033}

Submitted on 14 May 2020

HAL is a multi-disciplinary open access archive for the deposit and dissemination of scientific research documents, whether they are published or not. The documents may come from teaching and research institutions in France or abroad, or from public or private research centers.
L'archive ouverte pluridisciplinaire HAL, est destinée au dépôt et à la diffusion de documents scientifiques de niveau recherche, publiés ou non, émanant des établissements d'enseignement et de recherche français ou étrangers, des laboratoires publics ou privés. 


\section{Potassium Ions Enhance Guanine Radical}

\section{Generation upon Absorption of Low-Energy}

\section{Photons by G-quadruplexes and Modify Their}

\section{Reactivity}

Behnaz Behmand, ${ }^{1 \S}$ Evangelos Balanikas, ${ }^{1}$ Lara Martinez-Fernandez, ${ }^{2} *$ Roberto Improta, ${ }^{3}$ Akos Banyasz, ${ }^{4}$ Gérard Baldacchino ${ }^{1}$ and Dimitra Markovitsi ${ }^{1}$ *

1. LIDYL, CEA, CNRS, Université Paris-Saclay, F-91191 Gif-sur-Yvette, France

2. Departamento de Quiímica, Facultad de Ciencias, Modúlo13, Universidad Autónoma de Madrid, Campus de Excelencia UAM-CSIC, Cantoblanco, 28049 Madrid, Spain;

IADCHEM. Institute for Advanced Research in Chemistry, Universidad Autónoma de Madrid, 28049 Cantoblanco, Madrid, Spain

3. Istituto Biostrutture e Bioimmagini- Consiglio Nazionale delle Ricerche, Via Mezzocannone 16, I-80134 Napoli, Italy

4. Univ Lyon, ENS de Lyon, CNRS UMR 5182, Université Claude Bernard Lyon 1, Laboratoire de Chimie, F-69342 Lyon, France

\section{Corresponding Authors}

*lara.martinez@uam.es; dimitra.markovitsi@cea.fr 


\begin{abstract}
G-quadruplexes are formed by guanine rich DNA/RNA sequences in the presence of metal ions, which occupy the central cavity of these four-stranded structures. We show that these metal ions have a significant effect on the photogeneration and the reactivity of guanine radicals. Transient absorption experiments on G-quadruplexes formed by association of four TGGGGT strands in the presence of $\mathrm{K}^{+}$reveal that the quantum yield of one-photon ionization at $266 \mathrm{~nm}\left(8.1 \times 10^{-3}\right)$ is twice as high as that determined in the presence of $\mathrm{Na}^{+}$. Replacement of $\mathrm{Na}^{+}$by $\mathrm{K}^{+}$suppresses one reaction path involving deprotonated radicals, $(\mathbf{G}-\mathrm{H} 2)^{\bullet} \rightarrow(\mathbf{G}-\mathrm{H} 1)^{\bullet}$ tautomerization. Such a behavior shows that the underlying mechanisms are governed by dynamical processes, controlled by the mobility of metal ions, which is higher for $\mathrm{Na}^{+}$compared to $\mathrm{K}^{+}$. These findings may contribute to understand the UV-induced DNA damage and optimize optoelectronic devices based on four-stranded structures, beyond DNA.
\end{abstract}


TOC GRAPHICS

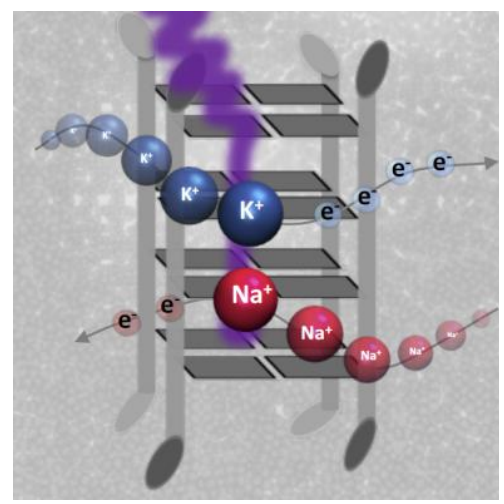


Characterizing the formation and subsequent reactivity of guanine (G) radicals is an important issue in respect to the oxidatively generated damage to DNA ${ }^{1}$ and the development of DNAbased electronic devices. ${ }^{2-3}$ Both aspects particularly concern G-quadruplexes, composed of vertically stacked $\mathbf{G}$ tetrads (Figure 1a). A quite unexpected route leading to $\mathbf{G}$ radicals in $\mathbf{G}-$ quadruplexes was reported recently: ${ }^{4-7}$ photoionization at energies significantly lower than the guanine vertical ionization potential (VIP). The resulting radicals were shown to follow a complex reaction path, involving deprotonation of the radical cations $\left(\mathbf{G}^{+\bullet} \rightarrow(\mathbf{G}-\mathrm{H} 2)^{\bullet}\right.$ and tautomerization of the deprotonated radicals $(\mathbf{G}-\mathrm{H} 2)^{\bullet} \rightarrow(\mathbf{G}-\mathrm{H} 1)^{\bullet}$ (Figure 1b). The present study is a stepping stone towards understanding this intriguing behavior. Performed by nanosecond transient absorption spectroscopy, it focuses on G-quadruplexes formed by association of four DNA TGGGGT strands in the presence of $\mathrm{K}^{+}$ions, $(\mathbf{T G 4 T})_{4} / \mathbf{K}^{+}$. The results are compared with those obtained for (TG4T) $)_{4} / \mathbf{N a}^{+}$, in which the static arrangement of nucleobases is the same, as determined by NMR experiments..$^{8-9}$ This is also attested by the identical steady-state UV absorption spectra exhibited by the two systems. ${ }^{9}$ It is shown that replacement of $\mathrm{Na}^{+}$by $\mathrm{K}^{+}$ leads to a twofold increase in the propensity of G-quadruplexes to eject an electron upon absorption of low-energy photons. This contrasts with their similar VIP values, computed for the first time for G-quadruplex structures using Density Functional Theory (DFT). Moreover, our experiments reveal that $\mathrm{K}^{+}$ions hinder tautomerization of deprotonated $\mathbf{G}$ radicals, readily observed in the presence of $\mathrm{Na}^{+}$ions. These findings pinpoint the role of metal ions, which are key elements of four-stranded architectures. ${ }^{10}$ In particular, the different mobility of $\mathrm{K}^{+}$and $\mathrm{Na}^{+}$ are likely to affect dynamical processes controlling both electron ejection and tautomerization. 
TGGGGT oligomers, purified by reversed phase HPLC, were studied in phosphate buffer $(0.15$ mol L-1 $\mathrm{KH}_{2} \mathrm{PO}_{4}, 0.15 \mathrm{~mol} \mathrm{~L}^{-1} \mathrm{~K}_{2} \mathrm{HPO}_{4}$ ). Details for $\mathbf{G}$-quadruplex preparation and handling are given in the Supporting Information (SI). They were excited by $5 \mathrm{~ns}$ laser pulses at $266 \mathrm{~nm}$ (Figure SI-1), with incident intensity lower than $2 \times 10^{6} \mathrm{Wcm}^{-2}$, thus avoiding two-photon ionization of the solvent.

a

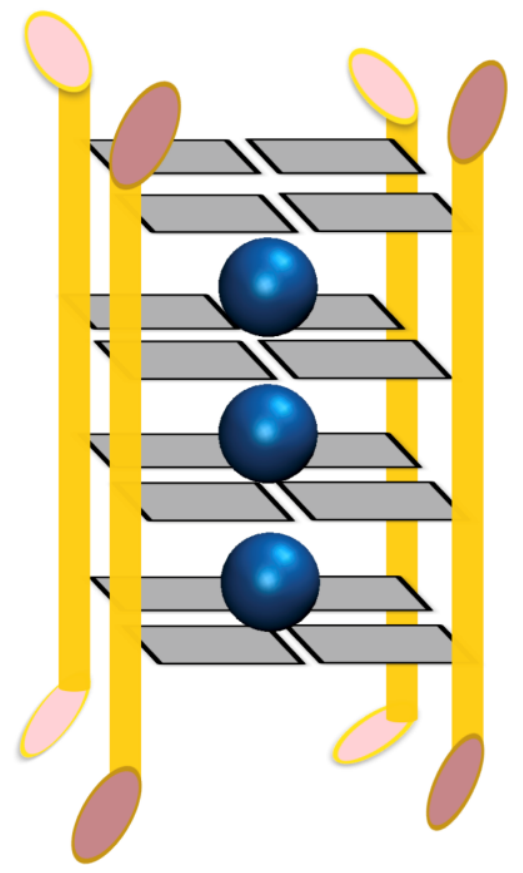

b

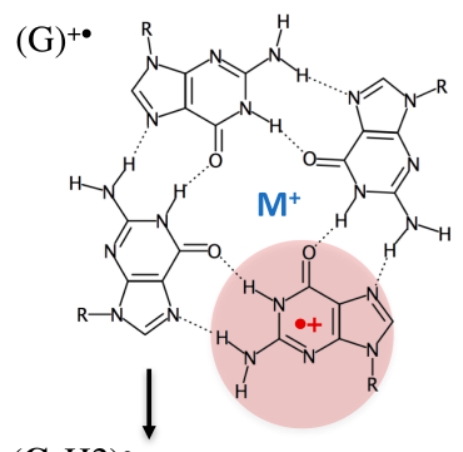

$(\mathbf{G}-\mathrm{H} 2)^{\circ}$

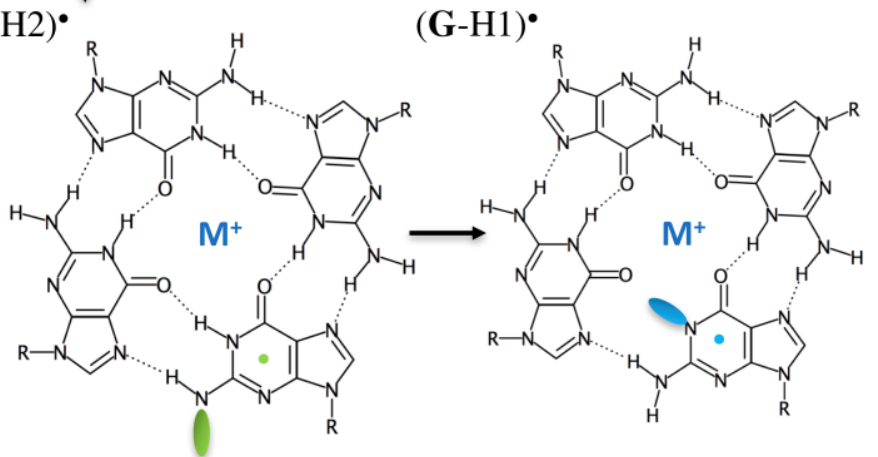

Figure 1. Schematic illustration of the G-quadruplex structure formed by association of four TGGGGT strands (a) and the three types of radicals generated upon photoionization (b). Blue spheres, parallelograms and ellipses in (a) represent, respectively, metal ions $\mathrm{M}^{+}$located in the central cavity of the G-quadruplex, guanine and thymine moieties.

Ejected electrons were quantified as a function of the exciting laser intensity by detecting their transient absorbance $\Delta \mathrm{A}$ on the sub- $\mu$ s time scale, when they had been already hydrated $\left(\mathrm{e}_{\text {hyd }}\right)^{11}$ exhibiting a broad absorption band peaking around $720 \mathrm{~nm}$. They disappear with a time constant 
of $0.5 \pm 0.1 \mu$ s (Figure 2a), being scavenged by the phosphate buffer in high concentration. Their decay was fitted with a mono-exponential function $A_{0}+A_{1} \exp \left(-t / \tau_{1}\right)$; the $A_{1}$ value, combined with the molar absorption coefficient of $\mathrm{e}_{\text {hyd }},{ }^{-11}$ provided their zero-time concentration $\left[\mathrm{e}_{\text {hyd }}\right]_{0}$. Upon varying the concertation of photons absorbed by the probed solution [hv], we obtained the ionization curve in Figure 2b, fitted with a linear function. The intercept at the origin provides the quantum yield for one-photon ionization $\phi_{1}$, while the slope is proportional to the yield of the two-photon ionization. Under the same experimental conditions, no hydrated electrons were detected for the mononucleotide dGMP. The $\phi_{1}$ value derived from Figure $2 \mathrm{~b},(8.1 \pm 0.5) \times 10^{-3}$, is twice as high as that determined for (TG4T) ${ }_{4} / \mathbf{N a}^{+},(3.5 \pm 0.5) \times 10^{-3} .5$
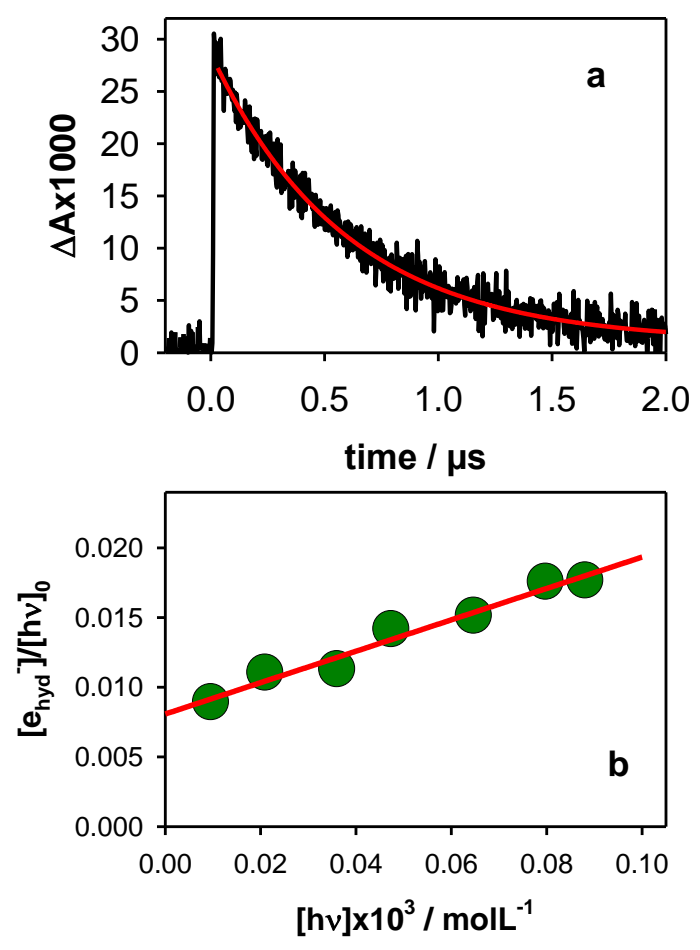

Figure 2. Quantification of hydrated electrons ejected from (TG4T) $)_{4} / \mathbf{K}^{+}\left(1.5 \times 10^{-5} \mathrm{molL}^{-1}\right)$ upon $266 \mathrm{~nm}$ excitation. (a) Transient absorption decay at $700 \mathrm{~nm}$ obtained with incident intensity of $1.7 \times 10^{6} \mathrm{Wcm}^{-2}$. (b) Ionization curve; $[\mathrm{hv}]$ and $\left[\mathrm{e}_{\mathrm{hyd}}\right]_{0}$ denote, respectively, the concentration of 
absorbed photons per laser pulse and the zero-time concentration of hydrated ejected electrons. Red lines represent fits with model functions: $\mathrm{A}_{0}+\mathrm{A}_{1} \exp \left(-\mathrm{t} / \tau_{1}\right)(\mathbf{a})$ and $\left[\mathrm{e}_{\mathrm{hyd}}{ }^{-}\right]_{0} /[\mathrm{hv}]=\phi_{1}+\alpha[\mathrm{hv}]$ (b).

Two different scenarios were invoked to explain G-quadruplex ionization by low-energy photons: $^{5-6}$ (A) the specific arrangement of guanines lowers their VIP, or (B) electron detachment occurs after excited state relaxation towards charge transfer (CT) states.

The effect of base-stacking and base-pairing on the VIP was found to be moderate. ${ }^{12-14}$ But, so far no information is available regarding G-quadruplexes, in which the central metal ions may have an influence. Thereby, we computed the VIP using a mixed quantum mechanics (QM)/molecular mechanics (MM) approach (Figure SI-2). As the large size of these systems makes the use of correlated methods, such as CASPT2, which provide accurate VIP values, ${ }^{15-17}$ too demanding, we worked at the DFT(M052X)/6-31G(d) level. However, test calculations on guanine in gas phase provided similar values at CASPT2 $(8.10-8.30 \mathrm{eV})$ and DFT $(8.00 \mathrm{eV})$ levels of theory (SI and Figure SI-3), the latter being also in agreement with previous DFT studies. ${ }^{12,}{ }^{18-20}$ The values found for $(\mathbf{T G 4 T})_{\mathbf{4}} / \mathbf{K}^{+}(6.48 \mathrm{eV})$ and $(\mathbf{T G 4 T})_{\mathbf{4}} / \mathbf{N a}^{+}(6.32 \mathrm{eV})=\mathrm{We}$ further examined the possibility that a small population exhibits lower VIP, due to inhomogeneous environment. Considering a Gaussian VIP distribution whose intensity is 1 at 6.5 $\mathrm{eV}$, a width of $\sim 1.3 \mathrm{eV}$ (FWHM) is required so that the intensity at $4.66 \mathrm{eV}(266 \mathrm{~nm})$ to be equal to the experimentally determined quantum yield $\left(\sim 8 \times 10^{-3}\right)$. Such a width is too large knowing that those corresponding to the lowest bright transition of nucleotides do not exceed $0.5 \mathrm{eV}^{21}$ Given all these considerations, scenario A, involving vertical ionization, does not seem plausible. 
The first step of scenario B implies population of an excited CT state. A recent computational study on TEL21/Na ${ }^{+}$identified two types of CT states, between two guanines of the Gquadruplex core on the one hand, and between a guanine and the thymine of the loop, on the other. ${ }^{22}$ Experimentally, the formation of low energy CT states during the excited state relaxation in G-quadruplexes has been evidenced by time-resolved fluorescence anisotropy studies. ${ }^{9,22-25} \mathrm{~A}$ low energy band is also present in the steady-state fluorescence spectra of dinucleotides dGpT (Figure SI-4). Moreover, in both (TG4T) $)_{4} / \mathbf{K}^{+}$and (TG4T) $)_{4} / \mathbf{N a}^{+}$, thymines form an additional tetrad for $15 \%$ of population, ${ }^{8}$ a configuration that may favor population of thymine-guanine CT states. According to the second step of scenario B, the positive charge is trapped by the guanine core, where it may be delocalized. ${ }^{26-27}$ This process is tentatively described as: $\mathrm{T}^{-} \mathrm{G}^{+} \mathrm{GGGT} \rightarrow \mathrm{T}^{-}(\mathrm{GGGG})^{+} \mathrm{T}$ or $\mathrm{TGG}^{-} \mathrm{G}^{+} \mathrm{GT} \rightarrow \mathrm{T}^{-}(\mathrm{GGGG})^{+} \mathrm{T}$. Finally, electron ejection, assisted by conformational motions, occurs from the thymine anion, whose VIP in the gas phase is lower than $0.1 \mathrm{eV}^{28}$

Coming to radicals, their spectra (Figure 3) are determined after the decay of $\mathrm{e}_{\text {hyd }}{ }^{-}$. As in the case of previously studied G-quadruplexes, ${ }^{4-6}$ the spectrum at $3 \mu \mathrm{s}$ exhibits a broad band in the visible, explained by the coexistence of $(\mathbf{G})^{+\bullet}$ and $(\mathbf{G}-\mathrm{H} 2)^{\bullet}$. When the transient absorbance $\Delta \mathrm{A}$ is divided by the $\left[\mathrm{e}_{\mathrm{hyd}}{ }^{-}\right]_{0}$ determined for the same excitation intensity, the radical spectrum can be quantitatively described by a linear combination of the $(\mathbf{G})^{+\bullet}$ and $(\mathbf{G}-\mathrm{H} 2)^{\bullet}$ spectra in a ratio 0.4/0.6 (Figure 3a), considering the corresponding spectra reported for either monomeric guanosines $^{29-30}$ or (TG4T) $)_{4} / \mathbf{N a}^{+5}$. The combined quantification of $\left[\mathrm{e}_{\text {hyd }}{ }^{-}\right]_{0}$ and $\mathbf{G}$ radicals reveals that $(40 \pm 5) \%$ of the initially generated electron holes are still present at $3 \mu \mathrm{s}$, a slightly higher percentage than that found for (TG4T) $)_{4} / \mathbf{N a}^{+},(25 \pm 5) \%{ }^{5}$ Deprotonation of this long-lived $(\mathbf{G})^{+\bullet}$ 
population, occurs practically within $\sim 10 \mu$ s (Figure $4 \mathrm{a}$ ), independently of the type of metal ions. ${ }^{5}$

The characteristic absorption band of $(\mathbf{G}-\mathrm{H} 2)^{\bullet}$ radicals, peaking around $600 \mathrm{~nm}$, is present in the spectra of (TG4T) $)_{4} / \mathbf{K}^{+}$on the ms time-scale (Figure 3b). Moreover, the decay patterns in the 500 $-650 \mathrm{~nm}$ region are quite similar (Figure 4b). This contrasts with the behavior of (TG4T) ${ }_{4} / \mathrm{Na}^{+}$, whose spectrum at $6 \mathrm{~ms}$ clearly corresponds to deprotonated $(\mathbf{G}-\mathrm{H} 1)^{\bullet}$ radicals and decay patterns are wavelength dependent. ${ }^{5}$ Furthermore, we found that the spectra computed for all $\mathbf{G}$ radicals are hardly affected by the type of the metal ions (Figure SI-5). Thus, it appears that the (G-H2) $\rightarrow(\mathbf{G}-\mathrm{H} 1)^{\bullet}$ tautomerization, which is operative for $(\mathbf{T G 4 T})_{4} / \mathbf{N a}^{+},{ }^{5}$ but also for telomeric $\mathbf{G}-$ quadruplexes TEL21/Na ${ }^{+}$, is practically suppressed in the case of $(\mathbf{T G 4 T})_{4} / \mathbf{K}^{+}$.

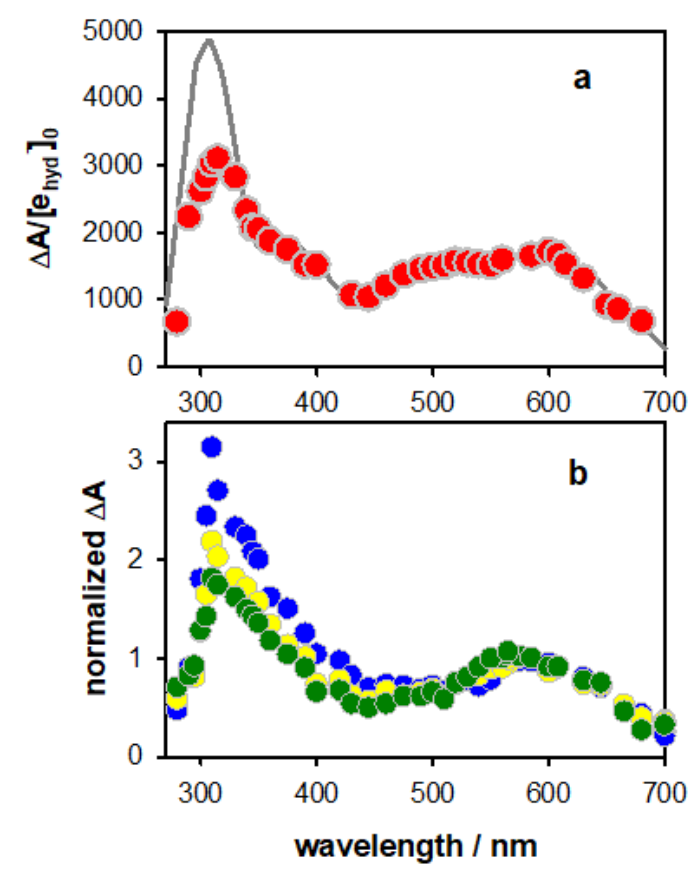


Figure 3. Differential absorption spectra determined for (TG4T) $)_{4} / \mathbf{K}^{+}$at $3 \mu \mathrm{s}(\mathbf{a}$; red), $100 \mu \mathrm{s}(\mathbf{b}$; green), $2 \mathrm{~ms}$ (b; yellow) and $6 \mathrm{~ms}$ (b; blue). In (a) $\Delta \mathrm{A}$ was divided by the initial concentration of hydrated ejected electrons $\left[\mathrm{e}_{\mathrm{hyd}}{ }^{-}\right]_{0}$; the grey line in (a): linear combination of the spectra corresponding to the radical cation $(40 \%)^{29}$ and the $(\mathbf{G}-\mathrm{H} 2)^{\bullet}$ radical of monomeric guanosine $(60 \%),{ }^{30}$ considered with their $\varepsilon$ values. $\Delta \mathrm{A}$ in (b) was normalized to 1 at $585 \mathrm{~nm}$.

Tautomerization of deprotonated radicals requires, in principle, breaking of a hydrogen bond (Figure 1b) which may be local or result from simple dissociation of the four-stranded structures. According to an NMR study, the dissociation rate of (TG4T) $)_{4} / \mathbf{N a}^{+}$is two orders of magnitude faster than that of $(\mathbf{T G 4 T})_{\mathbf{4}} / \mathbf{K}^{+} ;{ }^{31}$ but the associated times (days) are excessively longer compared to those found for radical tautomerization (a few ms). ${ }^{5}$ In contrast, the movement of the metal ions occurs on a time-sale comparable to our observations. ${ }^{10,32-33}$ The free energy barriers corresponding for moving of metal ions to adjacent binding sites, were reported to be 1315 and 4-5 $\mathrm{kcalmol}^{-1}$, respectively, for $(\mathbf{T G 4 T})_{4} / \mathbf{K}^{+}$and $(\mathbf{T G 4 T})_{4} / \mathbf{N a}^{+34}$ Such motions are expected to perturb the entire bond network inside tetrads. When radicals are present, there is competition between two reactions: $(\mathbf{G}-\mathrm{H} 2)^{\bullet} \rightarrow(\mathbf{G}-\mathrm{H} 1)^{\bullet}(\mathrm{I})$ and $(\mathbf{G}-\mathrm{H} 2)^{\bullet} \rightarrow \mathrm{X}(\mathrm{II})$, where $\mathrm{X}$ is an unknown DNA lesion. Thus, observation of $(\mathbf{G}-\mathrm{H} 1)^{\bullet}$ radicals is possible only if the rate of bond breaking is faster than the rate of reaction (II). In the case of (TG4T) $)_{4} / \mathbf{K}^{+}$, reaction (II) prevails, while the two rates are comparable for (TG4T) $)_{4} / \mathbf{N a}^{+}$. For the latter system, $40 \%$ of the $\mathbf{G}$ radical population is present as $(\mathbf{G}-\mathrm{H} 1)^{\bullet}$ at $10 \mathrm{~ms}$, while $60 \%$ has already reacted mainly via the $(\mathbf{G}-\mathrm{H} 2)^{\bullet}$ form.

It is worth-stressing that neither the radical concentration generated with a given excitation intensity, nor their decay pattern (Figure SI-6) are modified upon tenfold decrease of the ionic 
strength of the buffer. This means that, on the one hand, the screening of phosphate groups by counter ions does not affect the photo-ionization process and, on the other, the buffer ingredients do not participate to the $(\mathbf{G}-\mathrm{H} 2)^{\bullet} \rightarrow \mathrm{X}$ reaction.
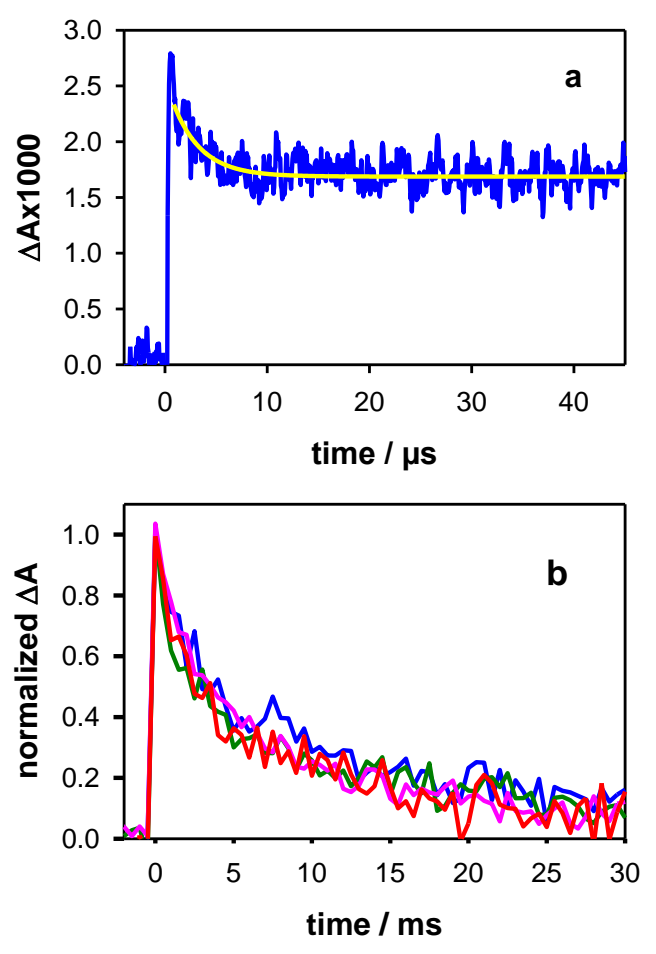

Figure 4. Transient absorption traces recorded for (TG4T) $)_{4} / \mathbf{K}^{+}$at $500 \mathrm{~nm}$ (blue) on the $\mu$ s (a) and the ms (b) time-scales. The yellow line in (a) corresponds to the fit with a mono-exponential function. The decays at $550 \mathrm{~nm}$ (green), $600 \mathrm{~nm}$ (pink) and $650 \mathrm{~nm}$ (red), normalized to their maximum, are also shown in (b). Excitation intensity of $2 \times 10^{6} \mathrm{Wcm}^{-2}$.

In conclusion, the larger propensity of $(\mathbf{T G 4 T})_{4} / \mathbf{K}^{+}$to undergo electron detachment by absorption of low-energy photons, compared to (TG4T) ${ }_{4} / \mathbf{N a}^{+}$, in association with their similar VIP, indicates that electron detachment occurs via a non-vertical process. We hope that these results will incite further experimental and theoretical studies to elucidate the various steps of 
this complex mechanism. This could have an impact on the design of optoelectronic devices inspired by guanine quadruplexes and potentially containing other functional molecules. ${ }^{35}$ Moreover, the suppression of the $(\mathbf{G}-\mathrm{H} 2)^{\bullet} \rightarrow(\mathbf{G}-\mathrm{H} 1)^{\bullet}$ tautomerization by $\mathrm{K}^{+}$ions, provides a unique occasion to identify the DNA lesions stemming from $(\mathbf{G}-\mathrm{H} 2)^{\bullet}$ radicals by analytical chemistry methods. Such a characterization will allow evaluating the overall biological impact of oxidative damage related to G-quadruplex structures. The existing studies mainly focus on the reaction products resulting from radical cations. ${ }^{36-37}$ Our results show instead that, in the presence of $\mathrm{K}^{+}$ions, more abundant than $\mathrm{Na}^{+}$ions in human cells, nearly the entire radical population is transformed to $(\mathbf{G}-\mathrm{H} 2)^{\bullet}$, whose reactivity so far has been neglected.

\section{ASSOCIATED CONTENT}

Supporting Information. Experimental Details; Computational Details; Additional Figures.

\section{AUTHOR INFORMATION}

The authors declare no competing financial interests.

\section{ACKNOWLEDGMENT}

The authors thank the 10751 the European Programme H2020 MSCA ITN [grant No. 765266 LightDyNAmics project], Plan Cancer [grant No. PC2016004, BITMAP project], LABEXPALM (ANR-10-LABX-0039-PALM, OSPEG project,) and the MINECO (CTQ2016-76061-P) for financial support. This work was performed using HPC resources from GENCI-IDRIS (Grant 2017-A0030810262). 


\section{REFERENCES}

1. Cadet, J.; Douki, T.; Ravanat, J.-L. Oxidatively Generated Damage to Cellular DNA by UVB and UVA Radiation. Photochem. Photobiol. 2015, 91, 140-155.

2. Livshits, G. I.; Stern, A.; Rotem, D.; Borovok, N.; Eidelshtein, G.; Migliore, A.; Penzo, E.; Wind, S. J.; Di Felice, R.; Skourtis, S. S.; Carlos Cuevas, J.; Gurevich, L.; Kotlyar, A. B.; Porath, D. Long-range charge transport in single G-quadruplex DNA molecules. Nature Nanotech. 2014, 9, 1040-1046.

3. Mergny, J. L.; Sen, D. DNA Quadruple Helices in Nanotechnology. Chem. Rev. 2019, $119,6290-6325$.

4. Banyasz, A.; Martinez-Fernandez, L.; Balty, C.; Perron, M.; Douki, T.; Improta, R.; Markovitsi, D. Absorption of Low-Energy UV Radiation by Human Telomere G-Quadruplexes Generates Long-Lived Guanine Radical Cations. J. Am. Chem. Soc. 2017, 139, 10561-10568.

5. Banyasz, A.; Balanikas, E.; Martinez-Fernandez, L.; Baldacchino, G.; Douki, T.; Improta, R.; Markovitsi, D.; 2019. Radicals generated in tetramolecular guanine quadruplexes by photo-ionization: spectral and dynamical features. J. Phys. Chem. B 2019, 123, 4950-4957.

6. Balanikas, E.; Banyasz, A.; Baldacchino, G.; Markovitsi, D. Populations and Dynamics of Guanine Radicals in DNA strands: Direct versus Indirect Generation. Molecules 2019, 24, 2347.

7. Daly, S.; Porrini, M.; Rosu, F.; Gabelica, V. Electronic spectroscopy of isolated DNA polyanions. Faraday Disc. 2019, 217, 361-382.

8. Sket, P.; Plavec, J. Tetramolecular DNA Quadruplexes in Solution: Insights into Structural Diversity and Cation Movement. J. Am. Chem. Soc. 2010, 132, 12724-12732.

9. Hua, Y.; Changenet-Barret, P.; Improta, R.; Vayá, I.; Gustavsson, T.; Kotlyar, A. B.; Zikich, D.; Šket, P.; Plavec, J.; Markovitsi, D. Cation Effect on the Electronic Excited States of Guanine Nanostructures Studied by Time-Resolved Fluorescence Spectroscopy. J. Phys. Chem. C 2012, 116, 14682-14689.

10. Hud, V.; Plavec, J. The role of cations in determining quadruplex structure and stability. In Quadruplex nucleic acids, Balasubramanian, S.; Neidle, S., Eds. RSC Publishing: Cambridge, 2006; pp 100-130.

11. Torche, F.; Marignier, J. L. Direct Evaluation of the Molar Absorption Coefficient of Hydrated Electron by the Isosbestic Point Method. J. Phys. Chem. B 2016, 120, 7201-7206.

12. Pluharova, E.; Slavicek, P.; Jungwirth, P. Modeling Photoionization of Aqueous DNA and Its Components. Acc. Chem. Res. 2015, 48, 1209-1217. 
13. Chakraborty, R.; Ghosh, D. The effect of sequence on the ionization of guanine in DNA. Phys. Chem. Chem. Phys. 2016, 18, 6526-6533.

14. Cauet, E.; Valiev, M.; Weare, J. H. Vertical Ionization Potentials of Nucleobases in a Fully Solvated DNA Environment. J. Phys. Chem. B 2010, 114, 5886-5894.

15. Matsika, S. Two- and three-state conical intersections in the uracil cation. Chem. Phys. 2008, 349, 356-362.

16. Roca-Sanjuan, D.; Rubio, M.; Merchan, M.; Serrano-Andres, L. Ab initio determination of the ionization potentials of DNA and RNA nucleobases. J. Chem. Phys. 2006, 125.

17. Segarra-Marti, J.; Tran, T.; Bearpark, M. J. Ultrafast and radiationless electronic excited state decay of uracil and thymine cations: computing the effects of dynamic electron correlation. Phys. Chem. Chem. Phys. 2019, 21, 14322-14330.

18. Pluharova, E.; Jungwirth, P.; Bradforth, S. E.; Slavicek, P. Ionization of Purine Tautomers in Nucleobases, Nucleosides, and Nucleotides: From the Gas Phase to the Aqueous Environment. J Phys Chem B 2011, 115, 1294-1305.

19. Schroeder, C. A.; Pluharova, E.; Seidel, R.; Schroeder, W. P.; Faubel, M.; Slavicek, P.; Winter, B.; Jungwirth, P.; Bradforth, S. E. Oxidation Half-Reaction of Aqueous Nucleosides and Nucleotides via Photoelectron Spectroscopy Augmented by ab Initio Calculations. J. Am. Chem. Soc. 2015, 137, 201-209.

20. Martinez-Fernandez, L. M.; Cerezo, J.; Asha, H.; Santoro, F.; Coriani, S.; Improta, R. The Absorption Spectrum of Guanine Based Radicals: a Comparative Computational Analysis. Chemphotochem 2019, 3, 846-855.

21. Bouvier, B.; Gustavsson, T.; Markovitsi, D.; Millié, P. Dipolar coupling between electronic transitions of the DNA bases and its relevance to exciton states in double helices. Chem. Phys. 2002, 275, 75-92.

22. Martinez-Fernandez, L.; Changenet, P.; Banyasz, A.; Gustavsson, T.; Markovitsi, D.; Improta, I. A Comprehensive Study of Guanine Excited State Relaxation and Photoreactivity in G-Quadruplexes. J. Phys. Chem. Lett. 2019, 10, 6873-6877.

23. Changenet-Barret, P.; Hua, Y.; Gustavsson, T.; Markovitsi, D. Electronic excitations in G-quadruplexes formed by the human telomeric sequence: a time-resolved fluorescence study. Photochem. Photobiol. 2015, 91, 759-765.

24. Hua, Y.; Changenet-Barret, P.; Gustavsson, T.; Markovitsi, D. The effect of size on the optical properties of guanine nanostructures: a femtosecond to nanosecond study. Phys. Chem. Chem. Phys. 2013, 15, 7396-7402.

25. Ma, C. S.; Chan, R. C.-T.; Chan, C. T.-L.; Wong, A. K.-W.; Kwok, W.-M. Real-time Monitoring Excitation Dynamics of Human Telomeric Guanine Quadruplexes: Effect of Folding Topology, Metal Cation, and Confinement by Nanocavity Water Pool. J. Phys. Chem. Lett. 2019, $10,7577-7585$. 
26. Sun, W. M.; Varsano, D.; Di Felice, R. Effects of G-Quadruplex Topology on Electronic Transfer Integrals. Nanomaterials 2016, 6 .

27. Martinez-Fernandez, L.; Banyasz, A.; Markovitsi, D.; Improta, I. Topology controls the electronic absorption delocalization of electron hole in guanine quadruplexes. Chem. Europ. J. 2018, 24, 15185-15189.

28. Schiedt, J.; Weinkauf, R.; Neumark, D. M.; Schlag, E. W. Anion spectroscopy of uracil, thymine and the amino-oxo and amino-hydroxy tautomers of cytosine and their water clusters. Chem. Phys. 1998, 239, 511-524.

29. Candeias, L. P.; Steenken, S. Stucture and acid-base properties of one-electron-oxidized deoxyguanosine, guanosine, and 1-methylguanosine. J. Am. Chem. Soc. 1989, 111, 1094-1099.

30. Chatgilialoglu, C.; Caminal, C.; Altieri, A.; Vougioukalakis, G. C.; Mulazzani, Q. G.; Gimisis, T.; Guerra, M. Tautomerism in the guanyl radical. J. Am. Chem. Soc. 2006, 128, 1379613805 .

31. Bardin, C.; Leroy, J. L. The formation pathway of tetramolecular G-quadruplexes. Nucleic Acids Res. 2008, 36, 477-488.

32. Rovnyak, D.; Baldus, M.; Wu, G.; Hud, N. V.; Feigon, J.; Griffin, R. G. Localization of Na-23(+) in a DNA quadruplex by high-field solid-state NMR. J. Am. Chem. Soc. 2000, 122, $11423-11429$.

33. Podbevsek, P.; Hud, N. V.; Plavec, J. NMR evaluation of ammonium ion movement within a unimolecular G-quadruplex in solution. Nucleic Acids Res. 2007, 35, 2554-2563.

34. Akhshi, P.; Mosey, N. J.; Wu, G. Free-Energy Landscapes of Ion Movement through a G-Quadruplex DNA Channel. Ang. Chem.-Int. Ed. 2012, 51, 2850-2854.

35. Xiao, S. J.; Davis, J. T. A G(4) $\mathrm{K}^{+}$hydrogel made from 5 '-hydrazinoguanosine for remediation of $\alpha, \beta$-unsaturated carbonyls. Chem. Comm. 2018, 54, 11300-11303.

36. Redstone, S. C. J.; Fleming, A. M.; Burrows, C. J. Oxidative Modification of the Potential G-Quadruplex Sequence in the PCNA Gene Promoter Can Turn on Transcription. Chem. Res.Toxicol. 2019, 32, 437-446.

37. Bielskute, S.; Plavec, J.; Podbevsek, P. Impact of Oxidative Lesions on the Human Telomeric G-Quadruplex. J. Am. Chem. Soc. 2019, 141, 2594-2603. 